\title{
Uso da plataforma ARDUINO na interdisciplinaridade do Ensino Fundamental I: Relato extensionista em uma escola pública
}

\author{
Alisson Diego Ramos ${ }^{1}$ \\ Fernanda Costa e Silva ${ }^{2}$ \\ Bruna Fontes Ferreira ${ }^{3}$ \\ Ricardo Rodrigues Magalhães ${ }^{4}$
}

Resumo: A procura por profissionais qualificados em áreas tecnológicas vem fazendo com que escolas convencionais se adaptem para este tipo de demanda. No entanto, estudantes de escolas públicas ainda têm dificuldades para assimilar conteúdos extraclasse. Algumas soluções educacionais vêm sendo implementadas nestas escolas e a robótica é uma delas. A Robótica Educacional (RE), como metodologia de ensino, conduz alunos na busca de soluções lógicas para os problemas a eles impostos. O objetivo deste trabalho é a implementação da RE por meio de encontros semanais entre tutores da Universidade Federal de Lavras e alunos do Ensino Fundamental I de uma escola pública da cidade de Lavras/MG. Como resultados, observou-se a melhoria no processo de aprendizagem escolar, melhoria no raciocínio lógico, maior interesse em atividades escolares e a utilização da criatividade em favor da aprendizagem.

Palavras chave: Aprendizagem; Robótica Educacional; Tecnologia.

\begin{abstract}
The demand for professionals in technological areas is causing conventional schools adaptation for this kind of demand. However, public school students still have difficulties to assimilate extra-class contents. Some educational solutions are being implemented in those schools and robotics is one of them. Educational Robotics (ER), as a teaching methodology, leads students to search for logical solutions to the problems imposed to them. The aim of this work is the implementation of ER through weekly meetings between tutors from University of Lavras and students from schools (elementary I level) located in the city of Lavras/MG - Brazil.
\end{abstract}

$1 \quad$ Estudante do Curso de Enga de Controle e Automação, UFLA, alissonramosadr@ hotmail.com. Estudante do Curso de Enga de Controle e Automação, UFLA, fernanda11879@yahoo.com.br. Estudante do Curso de Enga de Controle e Automação, UFLA, brunafontesufla@ gmail.com. Doutor em Engenharia Industrial, Universidade Federal de Lavras, ricardorm@deg.ufla.br. 
As results, it is observed the improvement in the school learning process and logical reasoning, greater interest in school activities and the use of creativity in benefit of learning.

Keywords: Learning, Educational Robotics, Technology.

\section{INTRODUÇÃO}

A educação tem como função fazer com que o homem conheça os elementos que o cercam, podendo intervir sobre eles, garantindo assim, a ampliação da sua liberdade, comunicação e colaboração com os seus semelhantes (Saviani, 2000). Neste contexto, a robótica educacional (RE) oferece novos horizontes para um processo de ensino-aprendizagem mais participativo, menos excludente quanto à ação do aluno na construção do conhecimento (Pinto, 2011). Desta forma, a inserção da robótica no processo educacional aparece como um grande recurso para que o aluno atue na construção do próprio conhecimento, aumentando as possibilidades de aprendizagem (Curcio, 2008).

A robótica surge nesse âmbito como uma ferramenta de inclusão tecnológica e pode ser definida como a ciência dos sistemas que interagem com o mundo real, com ou sem intervenção humana (Martins et al., 2009). Segundo o Dicionário Interativo da Educação Brasileira (2015), RE é um termo que caracteriza ambientes de aprendizagem que utilizam materiais de baixo custo ou kits educacionais compostos por peças diversas, sensores e atuadores controláveis por computadores e softwares, permitindo programar, de alguma forma, o funcionamento de modelos.

Esta metodologia de ensino, RE, é uma ideia que tomou força já na década de 80 , e vem se mostrando uma ferramenta eficiente que busca aliar os conceitos da Física, Matemática, Mecânica, Eletrônica, e Lógicas de Programação de uma forma interdisciplinar. Este recurso conduz as crianças na busca de soluções lógicas para os problemas a elas impostos, melhorando a maneira de expressar suas ideias, através da oralidade (Pinto, 2011).

A RE traz a interação entre professores e alunos através de trabalhos realizados em grupos que buscam explorar as variadas competências intelectuais das crianças, além de

Revista Extensão em Foco, nº 17, Out./ Dez. (2018), p. 120 - 132. 
proporcionar uma interdisciplinaridade com diversas disciplinas integrantes do ambiente da robótica educacional (Moraes, 2010).

A utilização de novas tecnologias vem sendo cada vez mais empregada em metodologias didáticas, possibilitando uma aprendizagem em um ambiente escolar mais interativo (Joly, 2002; Cavalcante, 2014).

Seguindo a linha da RE, a Olimpíada Brasileira de Robótica (OBR) é uma competição em que crianças e adolescentes devem desenvolver um robô seguidor de linha que execute, de maneira autônoma, os vários desafios contidos em uma pista (OBR, 2018). Para este tipo de competição (OBR), são geralmente utilizados robôs das plataformas Lego (Lego, 2018) ou Arduino (Arduino, 2018). A plataforma Arduino é considerada de baixo custo, fácil para prototipagem, destinada a estudantes sem experiência em eletrônica e programação. Esta plataforma tem sido o cérebro de milhares de projetos com variados graus de complexidade.

Nesse sentido, o objetivo deste trabalho foi a implementação da RE por meio de encontros semanais entre tutores da Universidade Federal de Lavras (UFLA) e alunos do Ensino Fundamental I (crianças do $1^{\circ}$ ao $5^{\circ}$ ano) de uma escola pública da cidade de Lavras/MG, utilizando a plataforma Arduino para fins de participação em competições da OBR, onde foram testados conhecimentos adquiridos pelos alunos em termos de programação e eletrônica básica.

\section{A UTILIZAÇÃO DA PLATAFORMA ARDUINO VOLTADA PARA ROBÔS SEGUIDORES DE LINHA}

A plataforma Arduino consiste em um hardware e um software livre para o desenvolvimento de projetos educativos, e também outros dispositivos eletrônicos, tais como sensores e atuadores. Os alunos trabalharam com o modelo MEGA, equipado com o microcontrolador ATMEGA2560.

Para a realização dos movimentos e manobras de robôs, são utilizados atuadores e sensores. Sensores de distância ultrassônico, tipo HC-SR04, são normalmente montados na parte frontal do robô, sensores de luz são normalmente montados na parte inferior do robô Revista Extensão em Foco, nº 17, Out./ Dez. (2018), p. 120 - 132. 
(LEDs emissores/receptores) e atuadores (servo motores) são normalmente montados nas laterais do robô para proporcionar movimento, conforme Figura 1.

Figura 1 - Posição dos sensores e atuadores no robô.

Legenda: 1. Sensor Ultrassônico. 2. Sensores de luz. 3. Atuador.

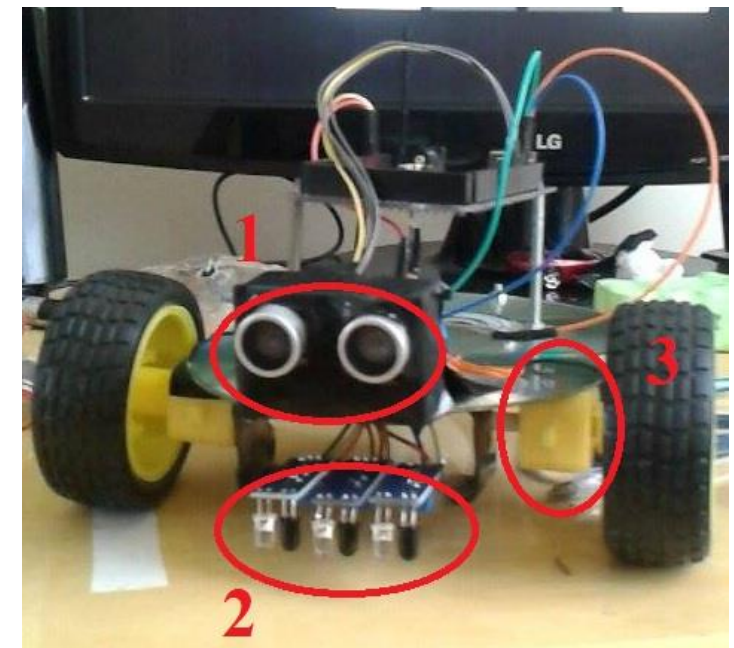

Fonte: Dos autores (2017).

A placa Arduino é programada utilizando algoritmos baseados na linguagem de programação C++. De acordo com Cuevas (2010) e Canudas (2012), para determinar um sistema de controle de trajetória, é necessário conhecer a trajetória ideal, que deve ser seguida durante o percurso, e a trajetória real, aquela executada pelo robô durante o percurso. Este sistema de controle atua levando em conta essas duas trajetórias, tentando minimizar a diferença entre elas.

De acordo com Menezes Filho (2010), é possível desenvolver um sistema de controle de posição, considerando a posição inicial do robô e a posição desejada. A partir das leituras Revista Extensão em Foco, nº 17, Out./ Dez. (2018), p. 120 - 132. 
dos sensores, é necessário modificar as velocidades para que a linha fique entre os sensores de luz. Neste projeto, para que os alunos pudessem definir a direção do robô de maneira simples, adotou-se a seguinte estratégia:

Se o LED receptor do sensor de luz do lado direito recebe reflexão (captou luz branca), então acione o motor do lado esquerdo.

- $\quad$ Se o LED receptor do sensor de luz do lado direito não recebe reflexão (não captou luz branca), então desligue o motor do lado direito.

- Se o LED receptor do sensor de luz do lado esquerdo não recebe reflexão (não captou luz branca), então desligue o motor do lado esquerdo.

- $\quad$ Se o Led receptor do sensor de luz do lado esquerdo recebe reflexão (captou luz branca), então acione o motor do lado direito.

A Figura 2 apresenta parte de um algoritmo utilizado em robôs seguidores de linha, mostrando o funcionamento dos motores a partir das leituras dos sensores de luz.

Figura 2 - Esquema utilizado para descrever atividades de um robô seguidor de linha

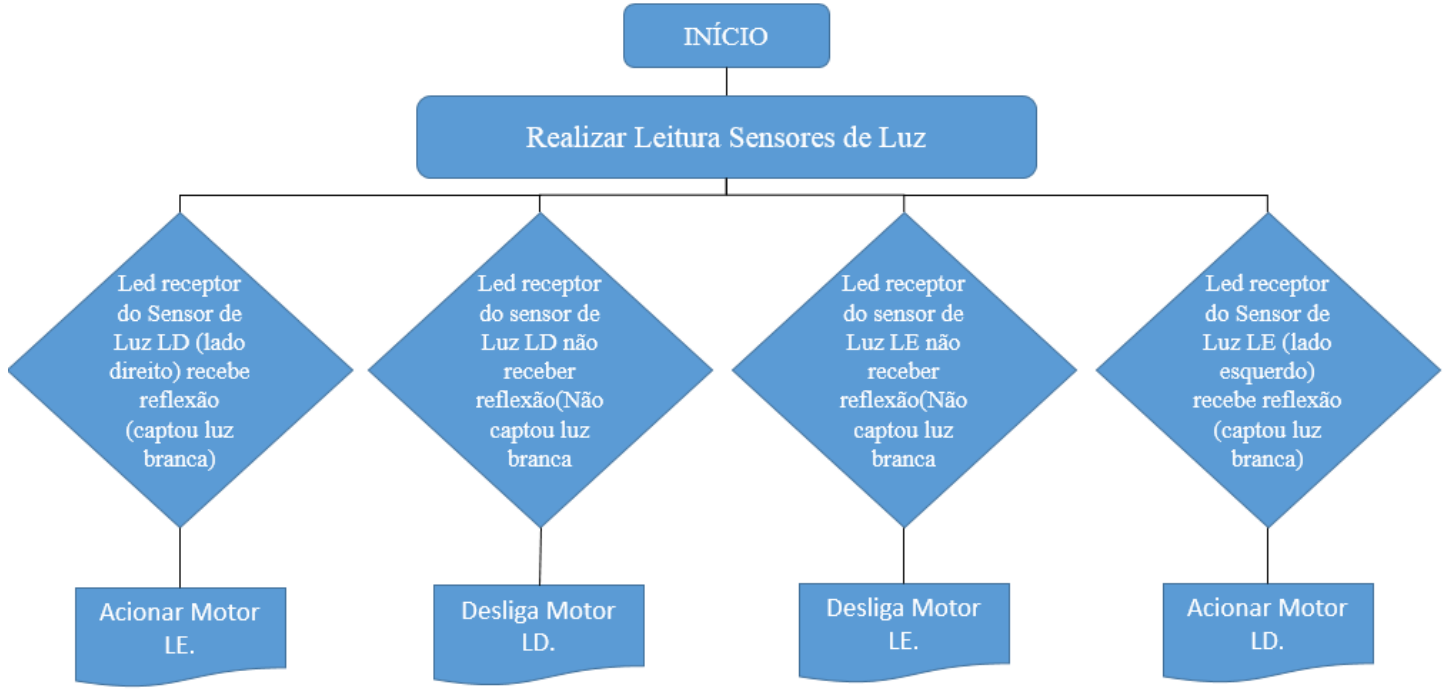

Fonte: Dos autores (2017).

\section{METODOLOGIA}

Revista Extensão em Foco, nº 17, Out./ Dez. (2018), p. 120 - 132. 


\section{A escolha dos alunos participantes do projeto}

O projeto intitulado "Robótica Educacional para Inclusão Social - REIS" é um projeto de extensão universitária conduzido na UFLA. A metodologia do projeto tem como base a pedagogia de projetos e aprendizagem significativa. Desta forma, foi desenvolvido um processo de tutoria, realizado por graduandos do curso de Engenharia de Controle e Automação da UFLA (voluntários e bolsistas de Extensão Universitária). Três tutores foram selecionados e capacitados para acompanhar e preparar os alunos participantes do projeto, visando a sua participação na OBR.

Os estudantes que participaram do projeto frequentavam o ensino fundamental I na escola pública Escola Municipal Professor José Luiz de Mesquita, localizada na cidade de Lavras - MG. A diretoria da escola realizou a escolha de doze alunos do ensino fundamental I, mais especificamente, alunos do $4^{\circ}$ e $5^{\circ}$ ano do ensino fundamental.

\section{A interação entre tutores e alunos}

Por meio de encontros semanais, os alunos participantes do projeto reuniam-se com os tutores, no intuito de adquirirem conhecimentos necessários de programação, desenvolvimento e montagem de um robô seguidor de linha. Cada tutor era responsável por uma equipe de 4 alunos. As seções (encontros semanais) ocorreram na UFLA, em um Laboratório equipado com vinte computadores e programas específicos instalados, proporcionando um ambiente agradável para as atividades propostas. Cada aluno desenvolvia as atividades individualmente em um computador dedicado, exceto quando as atividades ocorriam em grupo. As ferramentas utilizadas nos encontros eram, além dos componentes mecânicos e eletrônicos, projetor multimídia, quadro branco e pincéis.

Algumas dificuldades foram encontradas para a realização das seções, tais como, a inconsistência de horários entre tutores e alunos, eventual indisponibilidade de transporte para deslocamento dos alunos até a UFLA, eventual indisponibilidade do Laboratório na UFLA e a

Revista Extensão em Foco, nº 17, Out./ Dez. (2018), p. 120 - 132. 
incompatibilidade entre calendários escolares da UFLA e da escola. No entanto, todas as dificuldades foram superadas e os encontros ocorreram normalmente, exceto em algumas semanas, as quais tiveram suas atividades repostas com dois encontros por semana, no período próximo à competição da OBR.

\section{A preparação para a OBR}

A duração total do projeto foi de 48 semanas. Nas primeiras 14 semanas foram trabalhadas noções básicas de lógica computacional, para que os alunos tivessem noções básicas de programação para realizar as tarefas que os robôs deviam seguir em competições da OBR. Nas 14 semanas seguintes, trabalhou-se na montagem dos robôs, a partir de componentes mecânicos e eletrônicos. Nesta etapa, os alunos entenderam o funcionamento e a importância de cada componente utilizado. Nas últimas 20 semanas do projeto, foram desenvolvidos trabalhos de programação e teste das tarefas a serem executadas pelos robôs, no intuito de preparar os alunos para a competição regional da OBR edição 2017.

Durante a execução do projeto, adotou-se uma forma de trabalho em que um aluno pôde interagir com os colegas, debatendo e analisando conceitos, buscando encontrar diferentes maneiras de realizar os desafios propostos pelos tutores. Durante as atividades, os alunos depararam com situações que precisavam utilizar as habilidades adquiridas no treinamento para resolver exercícios, lidando com situações similares as que poderiam ocorrer durante a competição. Com isso, os alunos puderam desenvolver conhecimentos e competências interpessoais, além de habilidades para identificar e selecionar informações, tomar decisões, trabalhar em grupo e gerenciar conflitos.

Antes da realização das atividades propostas para a montagem dos robôs, os alunos passaram por um período de preparação, com a apresentação das peças e explicações sobre mecânica básica, funcionamento de motores, sensores, engrenagens, polias e conectores. Dessa forma, os alunos aprimoraram a capacidade de observação e raciocínio lógico.

Revista Extensão em Foco, nº 17, Out./ Dez. (2018), p. 120 - 132. 
Após a montagem dos robôs, os alunos receberam aulas de lógica sequencial, associando o conceito de algoritmos às situações do dia a dia, visto que a programação do robô pode, inicialmente, parecer complexa. Durante as primeiras aulas, os alunos aprenderam conceitos de lógica e uso de fluxogramas por meio de jogos educativos online. Posteriormente, os tutores introduziram conceitos básicos sobre o funcionamento de um software com linguagem de programação em $\mathrm{C}++$. Nesta etapa, foram utilizados inicialmente blocos lógicos para um melhor entendimento de programação, visto que eram crianças sem nenhum conhecimento prévio em programação.

Ao iniciar a programação, os alunos se depararam com problemas similares aos que enfrentariam em uma competição da OBR. Para solucionar os desafios, utilizaram os conhecimentos adquiridos nos estágios anteriores do projeto. Os alunos realizaram testes práticos em uma pista similar da OBR para identificar possíveis falhas, e utilizaram o trabalho em equipe para resolver problemas relacionados à programação e montagem dos robôs.

O passo final foi o desenvolvimento dos programas para participação da competição na OBR regional Minas Gerais, edição 2017. Assim, os alunos trabalharam com algoritmos mais complexos, lidando com falhas e frustrações, evidenciando o domínio na utilização das ferramentas apresentadas, visto que, durante a competição da OBR, eles trabalharam sem ajuda dos tutores. Para superar esse aspecto, foram realizadas competições internas entre as equipes participantes do projeto, evidenciando a importância do trabalho em equipe e da capacidade de solucionar problemas práticos.

Além disso, uma competição interna entre equipes dos tutores foi realizada, simulando uma competição da OBR, em que o propósito foi construir robôs seguidores de linha, usando a plataforma Arduino. Tal competição foi planejada para consolidar os conhecimentos dos tutores, além de servir como motivação para os alunos participantes do projeto. A competição interna ocorreu durante um evento extensionista organizado pela UFLA todo ano, no qual foram recebidos alunos de escolas de toda a região (UFLA de portas abertas). Tal fato possibilitou

Revista Extensão em Foco, nº 17, Out./ Dez. (2018), p. 120 - 132. 
grande visibilidade para o projeto, despertando o interesse não só dos participantes, mas também dos alunos que visitaram a universidade.

É importante ressaltar que, o envolvimento entre alunos e tutores se deu por meio deste projeto como sendo uma alternativa de trabalho extraescolar para melhorar eventuais deficiências no processo ensino-aprendizagem de disciplinas voltadas para as ciências exatas. Na metodologia empregada, levou-se em consideração que os estudantes são agentes da própria aprendizagem, produzindo algo que tenha utilidade prática, neste caso, os robôs.

Como metodologia de avaliação, utilizou-se a observação do rendimento dos alunos acerca das atividades propostas, visto que a avaliação do projeto foi realizada informalmente, com base na observação de motivação e relatos de professores e gestores escolares.

\section{RESULTADOS E DISCUSSÃO}

Por meio da implementação do projeto REIS para crianças do Ensino Fundamental I em uma escola pública, observou-se ao longo dos encontros, melhoria no raciocínio lógico, interação entre colegas e tutores, interesse em atividades extraescolares e a criatividade.

Observou-se, ainda, motivação dos alunos da Escola Municipal Professor José Luiz de Mesquita após competição OBR regional Minas Gerais, realizada no ano de 2017 (Figura 3).

Figura 3 - Equipe do Ensino Fundamental I na OBR edição 2017.

Revista Extensão em Foco, n 17, Out./ Dez. (2018), p. 120 - 132. 


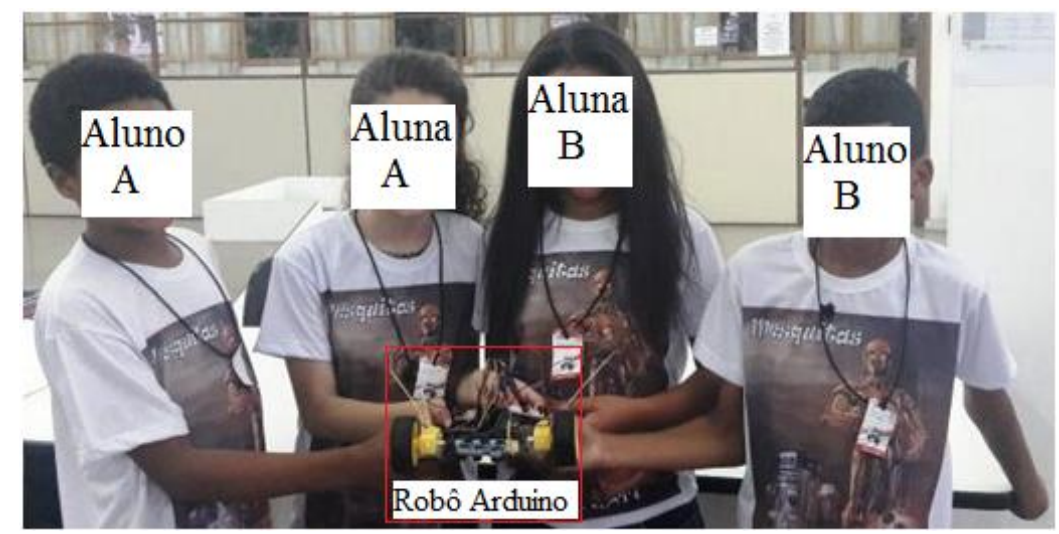

Fonte: http://www.lavras24horas.com.br/portal/equipe-mesquitas-de-robotica-retorna-as-atividades/

Notou-se que, mesmo não obtendo classificação satisfatória neste ano da competição, 2017, como em competições anteriores (Magalhaes, Marengo e Ferreira, 2015), observou-se que foi importante para a escola o fato dos alunos participarem deste tipo de competição, a qual estimula o raciocínio lógico, o trabalho em equipe e a criatividade. É importante ressaltar que em edições anteriores da OBR, este projeto foi desenvolvido para alunos do ensino fundamental II ( $6^{\circ}$ ao $9^{\circ}$ ano), no entanto, em 2017, foi implementado a plataforma Arduino para alunos do ensino fundamental $\mathrm{I}\left(1^{\circ}\right.$ ao $5^{\circ}$ ano $)$.

Ao programar e construir um robô seguidor de linha, a interdisciplinaridade se torna evidente, visto que são necessários conhecimentos em física (noções de velocidade, tempo e espaço para instalação e programação dos sensores), mecânica (montagem dos robôs) e eletrônica (montagem dos componentes eletrônicos). A matemática também foi trabalhada na utilização de algoritmos por meio do raciocínio lógico. Além disso, os códigos trabalhados no ambiente de desenvolvimento da plataforma Arduino necessitam de certo conhecimento do idioma inglês. Ao final do projeto, observou-se que os alunos foram capazes de contribuir com novas ideias de projeto e programação de robôs.

Todo este desenvolvimento pôde ser observado na etapa regional de Minas Gerais da OBR edição 2017, em que três equipes do $4^{\circ}$ e $5^{\circ}$ ano do ensino fundamental da Escola Municipal Professor José Luiz de Mesquita foram as únicas equipes da competição a utilizar a plataforma Arduino no nível I (crianças do ensino fundamental). Os alunos mostraram, apesar Revista Extensão em Foco, no 17, Out./ Dez. (2018), p. 120 - 132. 
da pouca idade, capacidade em lidar com inúmeros problemas que surgiram durante a competição sem qualquer ajuda dos tutores no momento da competição. A equipe também demonstrou atributos durante a competição, como capacidade de trabalho em equipe, agilidade em resolver desafios de caráter lógico e soluções criativas.

A partir da observação do rendimento dos alunos nas atividades propostas e também na competição, notou-se o desenvolvimento dos alunos, tanto em questões interdisciplinares quanto no comportamento em sala de aula, segundo relatos de professores e gestores escolares.

\section{CONCLUSÕES}

A OBR visa popularizar e difundir a ciência, usando a forma lúdica da competição como instrumento motivacional. Nesta linha, o projeto REIS possibilitou maior interação entre alunos do Ensino Fundamental I de uma escola pública e a universidade, visto que a RE estimula o pensamento crítico e a participação do aluno na construção do conhecimento.

Durante a realização do projeto, a participação nas competições motivou os envolvidos, refletindo no comportamento em sala de aula e na comunidade na qual se inserem. A introdução da RE aumentou o interesse dos alunos pelos estudos, melhorou o ambiente escolar e o convívio com os professores, segundo relatos de professores e gestores da escola participante do projeto.

Os resultados observados até o momento são promissores, levando-se em considerando a motivação dos alunos. Ao participar do projeto, os alunos foram incluídos no universo tecnológico, ampliando seus conhecimentos, e possibilitando-os escolherem carreiras nas áreas tecnológicas. Além disto, a difusão do projeto contribuiu para a inclusão social de várias crianças com vulnerabilidade socioeconômica, afastando-as de atividades ilícitas.

Contribuições deste trabalho não foram observadas somente para os alunos da escola participante, mas também para os alunos graduandos da universidade (tutores), pois não somente ensinaram, mas puderam aprender. Tecnicamente, os tutores puderam aperfeiçoar seus

Revista Extensão em Foco, no 17, Out./ Dez. (2018), p. 120 - 132. 
conhecimentos em linguagem de programação, mais especificamente, com a plataforma Arduino, que vem sendo cada dia mais utilizada, tanto na academia como no meio industrial. Em termos comportamentais, os tutores puderam vivenciar experiências de diferenças sociais, de pensamento e trabalho em equipe, além de acompanharem a participação dos alunos em uma importante competição de robótica. Como trabalhos futuros, propõe-se o uso de metodologias de avaliação, tais como, o estudo experimental do projeto e questionários para quantificar a importância deste tipo de projeto em ambientes escolares.

\section{Agradecimentos e apoios}

A Escola Municipal Professor José Luiz de Mesquita e a FAPEMIG.

\section{Referências Bibliográficas}

ARDUINO. Disponível em: 〈https://www.arduino.cc〉. Acesso em: Fevereiro 2018.

CANUDAS de Wit, Carlos; SICILIANO, BASTIN, Georges. Theory of robot control. Springer. Springer Science \& Business Media, 2012.

CAVALCANTE, Michelle M.; SILVA, João Lucas de S.; VIANA, Esdriane C.; DANTAS, Jamilson R. A Plataforma Arduino para fins didáticos: Estudo de casos com recolhimento de dados a partir do PXL-DAQ. In: XXXIV Congresso da Sociedade Brasileira de Computação - CSBC, p. 1687-1696, 2014.

CUEVAS, Erik; ZALDIVAR, Daniel; PÉREZ-CISNEROS, Marco. Low-cost commercial Lego $^{\text {TM }}$ platform for mobile robotics. International Journal of Electrical Engineering Education, v. 47 n. 2, p. 132-150, 2010.

CURCIO, Christina Paula de Camargo. Proposta de método de robótica educacional de baixo custo. 2008. Dissertação (Mestrado em Desenvolvimento de Tecnologia) - PRODETEC, Instituto de Tecnologia para o Desenvolvimento, Instituto de Engenharia do Paraná, Curitiba, 2008.

DICIONÁRIO INTERATIVO DA EDUCAÇÃO BRASILEIRA. Disponível em: $\langle\underline{\text { http://www.educabrasil.com.br/?q=Rob\%C3\%B3tica+educacional }>. ~ A c e s s o ~ e m: ~}$ Outubro 2016.

Revista Extensão em Foco, nº 17, Out./ Dez. (2018), p. 120 - 132. 
JOLY, Maria Cristina Rodrigues Azevedo. Tecnologia no ensino: implicações para a aprendizagem. São Paulo, Casa do Psicólogo, 2002.

LEGO. Disponível em: <https://www.lego.com/en-us/mindstorms>. Acesso em: Fevereiro 2018.

MAGALHAES, Ricardo Rodrigues; MARENGO, Rafael; FERREIRA, Nayara Janice. Robótica educacional para inclusão social: relato de uma experiência extensionista em Lavras/MG. Revista Ciência em Extensão, v.11, n.3, p.120-131, 2015.

MARTINS, Antonio Cesar Germano; SIMÕES, Alexandre da Silva; CARRION, Ronaldo SILVA, Kauê Cruz; MONTAGNOLI, Raquel Martins. Robótica como ferramenta de inclusão tecnológica. Extensão em Foco, n. 4, p. 211-218, 2009.

MENEZES FILHO, José Bezerra de. Controlador vetorial neural para mesa de coordenadas. Revista Controle \& Automação. v.21, n.4, p. 406-424, 2010.

MORAES, Maritza Costa. Robótica Educacional: Socializando e Produzindo Conhecimentos Matemáticos.2010. Dissertação apresentada ao Programa de Pós-Graduação em Educação em Ciências: Química da Vida e Saúde, Universidade Federal do Rio Grande FURG. Rio Grande, 2010.

OLIMPÍADA BRASILEIRA DE ROBÓTICA. Disponível em: <http://www.obr.org.br/>. Acesso em: Fevereiro 2018.

PINTO, Marcos de Castro. Aplicação de Arquitetura Pedagógica em curso de Robótica Educacional com Hardware Livre. Dissertação de Mestrado - Programa de Pós-Graduação em Informática - Universidade Federal do Rio de Janeiro. Rio de Janeiro, 2011.

SAVIANI, Dermeval. Educação - Do Senso Comum à Consciência Filosófica. Coleção educação contemporânea. Ed. Autores Associados: Campinas-SP, 13. ed., 2000.

ULLRICH, R. A. Robótica - Uma Introdução. O porquê dos robôs e seu papel no trabalho. Rio de Janeiro: Editora Campus, 1987.

Revista Extensão em Foco, nº 17, Out./ Dez. (2018), p. 120 - 132. 